\title{
The relationship between alexithymia, shame, trauma, and body image disorders: investigation over a large clinical sample
}

This article was published in the following Dove Press journal:

Neuropsychiatric Disease and Treatment

16 February 2013

Number of times this article has been viewed

\author{
Emilio Franzoni' \\ Stefano Gualandi' \\ Vincenzo Caretti ${ }^{2}$ \\ Adriano Schimmenti ${ }^{3}$ \\ Elena Di Pietro' \\ Gaetano Pellegrini' \\ Giuseppe Craparo ${ }^{3}$ \\ Arianna Franchi' \\ Alberto Verrotti ${ }^{4}$ \\ Alessandro Pellicciari' \\ 'Child Neuropsychiatry Unit, University \\ of Bologna, Italy; ${ }^{2}$ Department of \\ Psychology, University of Palermo, Italy; \\ ${ }^{3}$ Faculty of Human and Social Sciences, \\ Kore University of Enna, Enna, Italy; \\ ${ }^{4}$ Department of Pediatrics, University \\ of Chieti, Italy
}

Correspondence: Emilio Franzoni Child Neuropsychiatry Unit, Sant'Orsola Malpighi Hospital,Via Massarenti II, 40 I38, Bologna, Italy $\mathrm{Tel}+390516363994$

Email emilio.franzoni@unibo.it
Background: The connections between eating disorders (EDs) and alexithymia have not been fully clarified. This study aims to define alexithymia's connections with shame, trauma, dissociation, and body image disorders.

Methods: We administered the Dissociative Experience Scale-II, Trauma Symptom Inventory, Experience of Shame Scale, Toronto Alexithymia Scale-20, and Body Uneasiness Test questionnaires to 143 ED subjects. Extensive statistical analyses were performed.

Results: The subjects showed higher scores on alexithymia, shame, dissociation, and traumatic feelings scales than the nonclinical population. These aspects are linked with each other in a statistically significant way. Partial correlations highlighted that feelings of shame are correlated to body dissatisfaction, irrespective of trauma or depressed mood. Multiple regression analysis demonstrates that shame (anorexic patients) and perceived traumatic conditions (bulimic and ED not otherwise specified) are associated with adverse image disorders.

Conclusion: Shame seems to hold a central role in the perception of an adverse self-image. Alexithymia may be interpreted as being a consequence of previous unelaborated traumatic experiences and feelings of shame, and it could therefore be conceptualized as a maladaptivereactive construct.

Keywords: eating disorders, trauma, alexithymia, shame, body image

\section{Introduction}

Alexithymia is a construct characterized by the difficulty in identifying and describing feelings (affective factors), and by concrete and externally oriented thinking (cognitive factors). ${ }^{1}$ Eating disorders (EDs) are recognized in the Diagnostic and Statistical Manual of Mental Disorders-IV (DSM-IV) as separate disorders: anorexia nervosa (AN), bulimia nervosa (BN), and ED not otherwise specified (EDNOS). However, many people with serious EDs do not fit neatly into these categories, or they may change between categories over time. ${ }^{2}$ The etiologic multifactorial model where biological, individual, and environmental aspects interact seems to be the one that best explains the onset of EDs. ${ }^{3}$

The association between EDs and alexithymia has been widely demonstrated. For instance, Corcos et $\mathrm{al}^{4}$ identified that ED patients showed a statistically significant difference insofar as patients with ED were more likely to exhibit alexithymia when compared to a nonclinical population; these data were recently confirmed by Karukivi et $\mathrm{al}^{5}$ in a sample of older adolescents. Moreover, a prognostic study by Speranza et $\mathrm{al}^{6}$ investigating 102 ED patients demonstrated that difficulty in identifying feelings can act as a negative prognostic factor in the long-term outcomes of EDs. De Berardis et $\mathrm{al}^{7}$ studied 
the relationship between alexithymia, dissociative experiences, and low self-esteem in 546 undergraduate females, stating that a combination of these three constructs may represent risk factors for developing the symptoms of EDs. However, the relationship between EDs and alexithymia is not completely understood; ED patients that are being treated may continue to score high on measures of alexithymia, even when food-related abnormal behaviors have remitted. ${ }^{8}$ Moreover, the cognitive component of alexithymia does not appear to be related to EDs. ${ }^{9}$ Therefore, the relationship between EDs and alexithymia may be mediated by a third factor, ${ }^{10}$ and these two conditions are also associated with affective disorders. ${ }^{11}$

When looking for factors that may act as a link between alexithymia and EDs, the literature states that higher levels of dissociation are associated with severe bulimia, ${ }^{12}$ and that anorexic patients appear to use dissociation in order to avoid processing anger, ${ }^{13}$ it should be underlined that alexithymia and dissociation are both related to the failure of an individual to integrate his or her perceptions and emotions into his or her conscious experience. Dissociative experiences and alexithymia may be considered to be a coping mechanism that is used to alleviate painful emotions. ${ }^{14}$ In fact, nonelaborated and painful emotions produce a sense of tension that is perceived as dangerous for the subject's inner integrity, and, therefore, the dissociative mind states are possible defense mechanisms against anxiety. ${ }^{15}$

Among the various feelings experienced by ED patients, shame seems to play a central role. Shame can be regarded as the effect of dysregulated emotions experienced during childhood, ${ }^{16}$ which increase the possibility of dissociative mind states. ${ }^{17}$ Moreover, bodily shame has been found to predict an increase in anorexic symptoms. ${ }^{18}$ Thus, this study aims to investigate the presence of alexithymia in EDs.

With this research, we want to verify whether alexithymia could be associated with and have an influence on the structure of an adverse image disorder; however, the presence of other factors mediating the relationship between affective dysregulation and body image disorders has been postulated. ${ }^{10}$ Therefore, we investigated several variables that represent a core feature in the ED psychopathology - namely, dissociation, shame, affective disorders, and trauma - in order to determine which one may demonstrate a possible link between alexithymia and body image disorders in EDs.

\section{Methods}

We administered the following self-report tests: the Dissociative Experience Scale-II (DES-II), the Toronto Alexithymia Scale-20 (TAS-20), the Trauma Symptom
Inventory-Alternate Version (TSI-A), the Body Uneasiness Test (BUT), and the Experience of Shame Scale (ESS). These measures were chosen for their widely proven reliability, and given that they were available for adaptation and validation in Italian.

\section{Sample}

We consecutively recruited 143 female Italian subjects, aged 17 to 33 years, (average age 20.3 years, $\mathrm{SD} \pm 30.2$ ). The sample was composed of an outpatient population admitted to our ED center (Sant'Orsola, Malpighi, University of Bologna, Bologna, Italy). No males were included in the sample in order to improve sample homogeneity.

Diagnosis was performed according to DSM-IV criteria after a full psychiatric and psychological evaluation was performed by two trained clinicians. Patients were divided into $\mathrm{AN}, \mathrm{BN}$, or EDNOS groups. EDNOS patients were considered to exhibit patterns with mixed food restriction and purging characteristics that did not satisfy the DSM-IV criteria for $\mathrm{AN}$ or $\mathrm{BN}$.

A total of 67 patients received a diagnosis of AN (46.8\%), 52 of BN (36.3\%), and 24 (16.7\%) were considered to have an EDNOS. The average body mass index was 15.5 in the AN group, 18.6 in the BN group, and 16.8 in the EDNOS group.

\section{Procedures}

We administered five psychological self-reports during each patient's time of admission in our center. Before the tests were administered, we explained to the participants the general purpose of the study. The protocols were anonymous, and informed consent was provided by the patients' parents if the patients were underage. Subjects were selected only on the basis of their availability to complete the tests; compensation was not provided.

\section{DES-II}

DES-II is a widely used 28-item self-report that provides a quantitative index of dissociation. ${ }^{19}$ It has been found to be internally consistent and reliable over time. Its items are meant to capture a large variety of dissociative experiences. Item scores range from 0 to 100 , with the total score calculated as the mean of the 28 items. The Italian adaptation used in this study has good reliability characteristics, ${ }^{15}$ with an internal consistency that ranges from satisfactory to excellent (Cronbach's alpha of 0.81-0.94). Moreover, this scale is able to discriminate between subjects from normal populations and patients with addictions. ${ }^{19}$ The subjects' average score for 
the validation of the Italian instrument among a nonreferred population is $12.50(\mathrm{SD} \pm 8.62){ }^{20}$

\section{TAS-20}

The TAS-20 is the most widely used measure of alexithymia. ${ }^{21}$ Each item is rated on a five-point Likert-type scale, and responses range from strongly disagree (1) to strongly agree (5). Total scores range from 20 to 100 , with a score of $\geq 61$ considered to be indicative of alexithymia, while scores between 51 and 60 are considered to indicate borderline alexithymia. The TAS-20 has a three-factor structure:22 factor one assesses the ability of an individual to identify his or her feelings and to distinguish between feelings and the bodily sensations of emotional arousal (difficulty in identifying feelings); factor two reflects the inability of an individual to communicate his or her feelings to other people (difficulty in describing feelings); and factor three assesses externally oriented thinking. The Italian TAS-20 showed good internal consistency (Cronbach's alpha $=0.81$ ), and it contained the same three-factor structure as the English version of the scale.

\section{TSI-A}

The TSI-A is an 86-item self-report measure developed to assess a broad range of trauma-related symptoms. ${ }^{23}$ Each item is rated on a four-point, Likert-type scale $(0,1,2$, and 3$)$ that reflects the severity of symptoms. The TSI-A includes eight clinical scales and three validity scales. Five clinical scales (anxious arousal, depression, anger/irritability, intrusive experiences, and defensive avoidance) measure symptoms that are closely related to those listed in the DSM-IV for posttraumatic stress disorder. The other three clinical scales (dissociation, impaired self-reference, and tension-reduction behavior) measure additional symptoms often seen in trauma survivors, especially victims of childhood trauma. The three validity scales (response level, inconsistent response, and atypical response) measure exaggerated, inconsistent, or unusual responding. Average TSI-A scores in a nonclinical population is $1.01 \pm 0.5$.

\section{BUT}

The BUT is a self-rated scale that explores several areas of body image disorders and related psychopathologies. ${ }^{24}$ Participants were asked to rate 34 different body experiences (BUT-A) and 37 body parts (BUT-B) on a six-point Likert scale where responses ranged from never to always (0-5, respectively), indicating how often participants happened to dislike each experience or part of their body. The BUT scores were analyzed, while taking into account the whole mean score of the test (Global Severity Index [BUT-GSI]) and the number of body parts that the participant reported disliking on the BUT-B (Positive Symptom Total [BUT-PST]) subscale. Higher scores indicated greater body uneasiness.

\section{ESS}

The ESS is a 25-item scale whose items reflect the experiential (feeling shame), cognitive (concern over others' opinions), and behavioral (concealment or avoidance) components of shame. ${ }^{25}$ Participants rate each item according to how they have felt in the past year on a four-point scale, with responses ranging from 1 (not at all) to 4 (very much); total scores range from 25 (feelings of shame absent) to 100 (persistence of feelings of shame). The Italian adaptation of this scale shows good internal consistency (Cronbach's alpha $=0.93$ ), and it retains the same three-factor structure as the English version of the scale. The median score of this sample was 45.7 (SD \pm 13.1$)$. The cut-off score empirically obtained at the 95 th percentile is $73 .^{26}$

\section{Statistics}

The statistical analyses were carried out using the Statistical Package for the Social Sciences version (SPSS) 14.0.1 (IBM Corporation, Armonk, NY) for Windows (Microsoft Corporation, Redmond, WA). Data distribution was analyzed with skewness and kurtosis coefficients, and by applying the Kolmogorov-Smirnov test. Where possible, a normal distribution was obtained after logarithmic transformation of data with a nonnormal distribution. For normally distributed data, the statistical significance was assessed using Student's $t$-test, one-way analysis of variance (ANOVA) for multiple comparisons (Bonferroni test), Pearson's correlation index, and multiple regression analysis. For nonnormally distributed data, Mann-Whitney and Kruskal-Wallis tests, as well as Spearman's correlation index were used. A $P$-value of less than 0.05 (two-tailed) was considered to be statistically significant.

\section{Results}

First, the descriptive statistic indexes were extrapolated (Table 1). On average, the subjects presented with moderate to severe symptoms relative to the variables considered in our study. In fact, participants appeared to be borderline with regard to alexithymia (TAS-20 $=56.3 \pm 12$ ), and they presented with a shame score $(\mathrm{ESS}=67.4 \pm 19)$ of greater than the 90 th percentile when compared with the results from preliminary sample studies of Italian instrument validation. ESS 
Table I Average values $( \pm S D)$ of the total sample and each diagnostic group

\begin{tabular}{|c|c|c|c|c|}
\hline & $\begin{array}{l}\text { Anorexia nervosa } \\
(n=67)\end{array}$ & $\begin{array}{l}\text { Bulimia nervosa } \\
(n=52)\end{array}$ & $\begin{array}{l}\text { EDNOS patterns } \\
(n=24)\end{array}$ & $P$-value \\
\hline TAS-20 & $55.5 \pm 12.0$ & $57.7 \pm 12.2$ & $55.7 \pm 13.6$ & ns \\
\hline \multicolumn{5}{|c|}{ Alexithymia } \\
\hline $\mathrm{FI}$ & $3.03 \pm 0.92$ & $3.31 \pm 1.00$ & $3.12 \pm 1.15$ & ns \\
\hline \multicolumn{5}{|c|}{ Difficulty in identifying feelings } \\
\hline $\mathrm{F} 2$ & $3.18 \pm 0.95$ & $3.32 \pm 1.05$ & $3.23 \pm 1.06$ & ns \\
\hline \multicolumn{5}{|c|}{ Difficulty in describing feelings } \\
\hline F3 & $2.31 \pm 0.63$ & $2.21 \pm 0.67$ & $2.25 \pm 0.60$ & ns \\
\hline \multicolumn{5}{|c|}{ Externally oriented thinking } \\
\hline ESS & $63.6 \pm 17.8$ & $69.1 \pm 19.1$ & $74.4 \pm 18.5$ & $<0.05$ \\
\hline \multicolumn{5}{|c|}{ Shame feelings } \\
\hline DES-II & $17.6 \pm 12.9$ & $24.4 \pm 15.5$ & $26.7 \pm 19.4$ & $<0.05^{*}$ \\
\hline \multicolumn{5}{|c|}{ Dissociation } \\
\hline TSI-A & $1.15 \pm 0.50$ & $1.36 \pm 0.56$ & $1.39 \pm 0.55$ & ns \\
\hline \multicolumn{5}{|c|}{ Perceived traumatic experiences } \\
\hline TSI-A & $0.95 \pm 0.67$ & $1.28 \pm 0.77$ & $1.23 \pm 0.78$ & $<0.05$ \\
\hline \multicolumn{5}{|c|}{ Intrusive experiences } \\
\hline TSI-A & $1.38 \pm 0.6 \mathrm{I}$ & $1.6 \mathrm{I} \pm 0.77$ & $1.63 \pm 0.73$ & ns \\
\hline \multicolumn{5}{|c|}{ Impaired self-reference } \\
\hline TSI-A & $\mathrm{I} .48 \pm 0.8 \mathrm{I}$ & $1.82 \pm 0.79$ & $\mathrm{I} .84 \pm 0.89$ & $<0.05$ \\
\hline \multicolumn{5}{|c|}{ Depression } \\
\hline TSI-A & $\mathrm{I} .00 \pm 0.6 \mathrm{I}$ & $\mathrm{I} .4 \mathrm{I} \pm 0.74$ & $1.39 \pm 0.76$ & $<0.005$ \\
\hline \multicolumn{5}{|c|}{ Dissociation } \\
\hline BUT-GSI & $1.84 \pm 1.15$ & $2.50 \pm 1.19$ & $2.55 \pm 1.22$ & 0.005 \\
\hline \multicolumn{5}{|c|}{ Global severity index } \\
\hline BUT-PST & $18.2 \pm 10.2$ & $20.8 \pm 9.7$ & $24.2 \pm 11.6$ & 0.05 \\
\hline \multicolumn{5}{|c|}{ Positive symptom total } \\
\hline BUT-A & $2.47 \pm 1.41$ & $3.19 \pm 1.34$ & $3.04 \pm 1.28$ & $0.05^{*}$ \\
\hline \multicolumn{5}{|c|}{ Fear of weight gain } \\
\hline BUT-A & $2.06 \pm 1.34$ & $2.62 \pm 1.36$ & $2.75 \pm 1.44$ & 0.005 \\
\hline \multicolumn{5}{|c|}{ Body image concerns } \\
\hline BUT-A & $1.19 \pm 1.12$ & $1.77 \pm 1.34$ & $2.10 \pm 1.25$ & 0.005 \\
\hline \multicolumn{5}{|l|}{ Avoidance } \\
\hline BUT-A & $1.56 \pm 1.25$ & $2.19 \pm 1.28$ & $2.47 \pm 1.33$ & 0.005 \\
\hline
\end{tabular}

Notes: Statistically significant differences as detected by ANOVA and Kruskal-Wallis test. One-way analysis of variance for multiple comparisons (Bonferroni test) and Kruskal-Wallis test*.

Abbreviations: EDNOS, eating disorder not otherwise specified; TAS-20, Toronto Alexithymia Scale-20; FI, factor one; F2, factor two; F3, factor three; ESS, Experience of Shame Scale; DES-II, Dissociative Experience Scale-II; TSI-A, Trauma Symptom Inventory-Alternate Version; BUT-GSI, Body Uneasiness Test Global Severity Index; BUT-PST, Body Uneasiness Test Positive Symptom Total; BUT-A, Body Uneasiness Test Global Severity Index; ns, not significant.

average score in the Italian population is 45.72 , SD $13 . .^{15,20}$ Moreover, even if the cut-off score for dissociative disorders in DES-II was 30, the dissociation scores appeared to increase (DES-II $=21.6 \pm 15)$ if compared with the average range observed in the nonreferred population from the Italian sample $(12.5 \pm 8)$; the average values of the perceived traumatic conditions (weighted average TSI-A $=1.26 \pm 0.5$ ) in our sample are higher than those obtained from a nonclinical population. ${ }^{27} \mathrm{~A}$ total of 86 patients $(60 \%)$ showed symptoms of depressed mood as detected by the TSI-A depression scale. Finally, with regard to the body image disorders, there was evidence that participants had such a disorder across both the psychological and behavioral subscales (BUT-GSI $=2.2 \pm 1.2$, average scores of normal population $0.45-0.75$ ), and with respect to the level of dissatisfaction participants exhibited towards specific aspects of their bodies (BUT-PST $=20.2 \pm$ $10)$. These results appear to be only marginally influenced by patients' age (Table 2).

We have compared the three different diagnostic groups in order to detect statistically significant differences in some of the investigated psychopathologic areas. The one-way ANOVA was performed when variables followed a normal distribution, while the Kruskal-Wallis test was used when a normal distribution was not obtained. The ANOVA 
Table 2 Correlations between subjective measures and patients' age

\begin{tabular}{lllllll}
\hline Total ED sample & BUT-GSI & BUT-PST & ESS & TAS-20 & TSI-A & DES-II \\
\hline Correlation index vs age & $r=0.205$ & $r=0.178$ & $r=0.176$ & $r=-0.049$ & $r=0.068$ & $r=0.017$ \\
(level of significance) & $(P<0.05)$ & $(P<0.05)$ & $(P<0.05)$ & $(n s)$ & (ns) & (ns) \\
\hline
\end{tabular}

Abbreviations: ED, eating disorder; BUT-GSI, Body Uneasiness Test Global Severity Index; BUT-PST, Body Uneasiness Test Positive Symptom Total; ESS, Experience of Shame Scale; TAS-20, Toronto Alexithymia Scale-20; TSI-A, Trauma Symptom Inventory-Alternate Version; DES-II, Dissociative Experience Scale-Il; ns, not significant.

results showed statistically significant differences between the groups for the following dependent variables: ESS, $P<0.05$; TSI-A intrusive experiences, $P<0.05$; TSI-A depression, $P<0.05$; TSI-A dissociation, $P<0.005$; BUT dissatisfaction concerning body and weight, $P<0.005$; BUT avoidance and compulsive control behavior, $P<0.005$; BUT depersonalization (feelings of detachment and estrangement from the body), $P<0.005$; BUT-PST, $P<0.05$; the Kruskal-Wallis test detected a statistical significance with regard to the DES-II value $(P<0.05)$. We used the post hoc Bonferroni test in order to verify where the discrepancies among the investigated psychopathologies could be found; we observed that regarding ESS, the subjects with AN exhibited less feelings of shame than subjects who had a diagnosis that overlapped with $\mathrm{AN}$ and $\mathrm{BN}(P<0.05)$. With regard to the TSI-A, the $\mathrm{BN}$ group showed higher perceived intrusive experiences $(P<0.05)$ and higher dissociation $(P<0.01)$ than the AN group. Meanwhile, on the BUT-A scale, the BN group and EDNOS group showed higher values of altered body image $(P<0.05)$, avoidance and compulsive control ( $P<0.05$ and $P<0.01$, respectively), and depersonalization $(P<0.05)$. The group with the overlapping diagnosis also showed higher values on the BUT-PST subscale $(P=0.05)$ when compared to the results from the AN group. The Kruskall-Wallis test detected that the BN and the EDNOS groups showed higher values of dissociation on the DES-II test $(P<0.05)$.

We have performed correlation studies in order to verify how the investigated variables are related. By performing Pearson's and Spearman's correlations, we found that TSI-A, TAS-20, DES-II, and ESS are linked together in a statistically significant manner. When considering the AN group, we noticed that TAS-20 scores correlate with ESS scores $(\mathrm{r}=0.55, P<0.0001)$, DES-II scores $(\mathrm{r}=0.49$, $P<0.0001)$, and TSI-A perceived traumatic conditions ( $\mathrm{r}=0.47, P<0.0001)$. In addition, ESS scores correlate with DES-II scores $(\mathrm{r}=0.51, P<0.0001)$ and TSI-A scores $(\mathrm{r}=0.71, P<0.0001)$. Moreover, DES-II and TSI-A scores are also correlated $(\mathrm{r}=0.62, P<0.0001)$. In the $\mathrm{BN}$ group, TAS-20 correlates with ESS $(\mathrm{r}=0.39, P<0.01)$, DES-II $(\mathrm{r}=0.46, P=0.001)$, and TSI-A scores $(\mathrm{r}=0.52, P<0.001)$.
ESS scores correlate with DES-II $(\mathrm{r}=0.53, P<0.0001)$ and TSI-A scores $(\mathrm{r}=0.61, P<0.0001)$; DES-II scores correlate with TSI-A scores $(\mathrm{r}=0.66, P<0.0001)$. In the EDNOS group, TAS-20, TSI-A, and DES-II scores correlate with each other $(\mathrm{r}=0.53, P<0.05$ between TAS-20 and DES-II; $\mathrm{r}=0.47, P=0.05$ between TAS-20 and TSI-A; and $\mathrm{r}=0.55$ and $P<0.05$ between DES-II and TSI-A), while ESS scores correlate with some of the TSI-A subscales: anger/irritability $(\mathrm{r}=0.45, P<0.05)$, depression $(\mathrm{r}=0.49 ; P<0.05)$, and impaired self-reference $(\mathrm{r}=0.61, P<0.005)$ (Table 3).

The relationship between shame and alexithymia was studied in-depth using Bonferroni's test. As the total sample was subdivided on the basis of TAS-20 scores, ESS scores progressively increased. A $P<0.01$ was detected between ESS scores in nonalexithymic $(\mathrm{ESS}=55.8 \pm 17)$ and borderline alexithymic subjects (ESS $=68.1 \pm 14$ ), while $P<$ 0.0001 was detected between shame scores in nonalexithymic and pathologically alexithymic subjects $(\mathrm{ESS}=74.8 \pm 19)$. We then analyzed how these variables interact with results from the BUT scale (Table 4). In the AN group, we noticed that BUT-GSI scores correlate with each of the mentioned variables with a $P$-value $<0.0001(\mathrm{r}=0.48$ with TAS-20; $\mathrm{r}=0.71$ with ESS; $\mathrm{r}=0.44$ with TSI-A and DES-II), while BUT-PST correlates with the first factor of TAS-20 $(r=0.58)$, ESS $(r=0.49)$, TSI-A $(r=0.49)$, and DES-II $(r=0.44)$ with a $P$-value $<0.0001$. In the group composed of BN patients, we found that BUT-GSI also correlates with ESS $(r=0.67)$, DES-II $(\mathrm{r}=0.66)$, the first factor of TAS-20 $(\mathrm{r}=0.54)$, each with $P<0.0001$ and TSI-A $(\mathrm{r}=0.54$ and $P<0.001$, with a higher correlation noted with regard to depression and dissociation subscales). In addition, BUT-PST correlates with the TSI-depression subscale $(\mathrm{r}=0.48, P<0.0001)$, ESS ( $\mathrm{r}=0.38, P<0.01)$, DES-II $(\mathrm{r}=0.31)$, and the first factor of the TAS-20 $(\mathrm{r}=0.35)$ with $P<0.05$. Finally, BUT-GSI correlates with the first factor of the TAS-20 $(\mathrm{r}=0.65)$, TSI-A $(\mathrm{r}=0.53)$ with $P<0.001$, DES-II $(\mathrm{r}=0.55, P<0.01)$, and ESS $(r=0.49, P<0.05)$ in the EDNOS group. No correlation was found with regard to the BUT-PST subscale.

In the total ED patients sample, post hoc correlations were used to explore how perceived traumatic conditions influence experiences of shame (as measured by ESS) and 


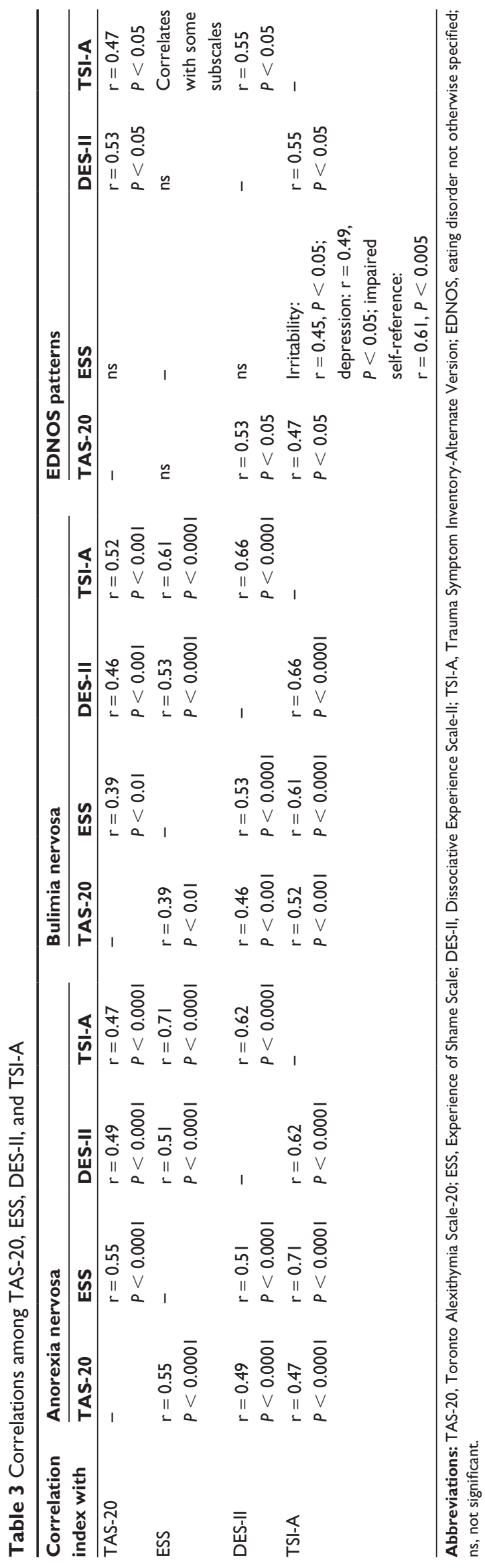

body dissatisfaction (as investigated by BUT-A and BUT-B). Bonferroni's test revealed that ESS and BUT values increase in a statistically significant manner $(P<0.0001)$ when TSI-A scores are indicative of a pathology.

Finally, through stepwise linear regression analysis between the considered variables we have detected those that explain, in a statistically significant manner, the body image disorders observed in EDs. We found different results among the three diagnostic groups (Table 4).

When considering the AN group, with regard to BUTGSI scores, the independent variable selected through the stepwise method included feelings of shame (ESS), which explain the $53 \%$ of the total variance in the BUT-GSI subscale $\left(\mathrm{R}^{2}=0.53, P<0.0001\right)$. With regard to the BUT-PST scores, the variable most predictive of body image disorders in ED is the first factor of the TAS-20 (difficulty in identifying feelings, $\mathrm{R}^{2}=0.33, P<0.0001$ ), which explains $33 \%$ of the total variance. In the BN group, BUT-GSI scores are strongly predicted by feelings of shame $\left(\mathrm{ESS}, \mathrm{R}^{2}=0.58, P<0.0001\right)$ and by the TSI-A dissociation subscale $\left(\mathrm{R}^{2}\right.$ change $=0.08$, $P<0.01)$. The TSI-A depression subscale appeared to be predictive of the level of body dissatisfaction measured by the BUT-PST subscale $\left(\mathrm{R}^{2}=0.29, P<0.0001\right)$, explaining $29 \%$ of its variance. Finally, in the EDNOS group, BUT-GSI scores were explained by perceived traumatic conditions (TSI-A, $\mathrm{R}^{2}=0.69, P<0.001$ ).

The influence of depression on the aforementioned variables has also been investigated. In the total sample of ED patients, the TSI-A depression subscale values correlate with TAS-20 $(r=0.51)$, ESS $(r=0.68)$, BUT-A $(r=0.69)$, and BUT-PST scores $(r=0.48$, as previously mentioned). These values reached a level of statistical significance of $P<0.0001$. However, when partial correlation analysis filtered the effects determined by the ESS results, no statistically significant correlation was determined between the TSI-A depression subscale and the BUT-PST results ( $\mathrm{r}=0.13 ; P>0.05)$, and the correlation between the TSI-A depression subscale and BUT-A scores appears to be moderate $(\mathrm{r}=0.27, P=0.01)$. Stepwise regression analysis instead showed that TSI-A depression values can be explained by BUT-A and ESS scores $\left(\mathrm{R}^{2}=0.51, P<0.001\right)$. Analogous data were obtained when partial correlation analysis filtered the effects of shame (ESS) on the relationship between results on the TSI-A and BUT scales. Instead, when the effects of perceived traumatic conditions are not considered by partial correlations, a strong correlation between ESS and BUT scores is maintained $(\mathrm{r}=0.53$ between ESS and BUT-A; $\mathrm{r}=0.39$ between ESS and BUT-PST; $P<0.0001$ ). 
Table 4 Correlations between BUT-GSI and BUT-PST and the other variables

\begin{tabular}{|c|c|c|c|c|c|c|}
\hline \multirow{2}{*}{$\begin{array}{l}\text { Dependent } \\
\text { variable }\end{array}$} & \multicolumn{2}{|l|}{ Anorexia nervosa } & \multicolumn{2}{|l|}{ Bulimia nervosa } & \multicolumn{2}{|l|}{ EDNOS patterns } \\
\hline & BUT-GSI & BUT-PST & BUT-GSI & BUT-PST & BUT-GSI & BUT-PST \\
\hline Correlation & ESS & ESS & ESS & DES-II & TSI-A & No \\
\hline \multirow[t]{13}{*}{ index vs } & $r=0.71$ & $r=0.49$ & $r=0.67$ & $r=0.3 \mathrm{I}$ & perceived traumatic & correlation \\
\hline & $P<0.0001$ & $P<0.000 I$ & $P<0.000 I$ & $P<0.05$ & conditions & \\
\hline & TAS-20 & TSI-A & TSI-A & TAS-20 FI & $r=0.53$ & \\
\hline & $r=0.48$ & Perceived traumatic & depression & $r=0.35$ & $P<0.0001$ & \\
\hline & $P<0.000 I$ & conditions & $r=0.66$ & $P<0.05$ & TAS-20 FI & \\
\hline & TSI-A & $r=0.49$ & $P<0.0001$ & ESS & $r=0.65$ & \\
\hline & Perceived traumatic & $P<0.000 I$ & TSI-A & $r=0.38$ & $P<0.0001$ & \\
\hline & conditions & TAS-20 FI & dissociation & $P<0.01$ & DES-II & \\
\hline & $r=0.44$ & $r=0.58$ & $r=0.59$ & TSI-A & $r=0.55$ & \\
\hline & $P<0.0001$ & $P<0.000 I$ & $P<0.0001$ & depression & $P<0.01$ & \\
\hline & DES-II & DES-II & TAS-20 FI & $r=0.48$ & ESS & \\
\hline & $r=0.44$ & $r=0.44$ & $r=0.54$ & $P<0.0001$ & $r=0.49$ & \\
\hline & $P<0.0001$ & $P<0.000 I$ & $P<0.000 \mathrm{I}$ & & $P<0.05$ & \\
\hline Multiple & ESS & TAS-20 FI & ESS & TSI-A depression & TSI-A & \\
\hline \multirow[t]{5}{*}{ regression vs } & $\mathrm{R}^{2}=0.53$ & $\mathrm{R}^{2}=0.33$ & $\mathrm{R}^{2}=0.58$ & $R^{2}=0.29$ & perceived traumatic & \\
\hline & $P<0.000 I$ & $P<0.000 I$ & $P<0.0001$ & $P<0.0001$ & conditions & \\
\hline & & & TSI-A dissociation & & $R^{2}=0.69$ & \\
\hline & & & $R^{2}=0.08$ & & $P<0.0001$ & \\
\hline & & & $P<0.00 I$ & & & \\
\hline
\end{tabular}

Abbreviations: BUT-GSI, Body Uneasiness Test Global Severity Index; BUT-PST, Body Uneasiness Test Positive Symptom Index; EDNOS, eating disorder not otherwise specified; ESS, Experience of Shame Scale; TAS-20, Toronto Alexithymia Scale-20; TSI-A, Trauma Symptom Inventory-Alternate Version; DES-II, Dissociative Experience Scale-II; FI, factor one.

\section{Discussion}

A co-presence of alexithymia and altered body image has been widely demonstrated in clinical and nonclinical ED samples. This study was carried out with a large clinical sample, and it aimed to determine if the structuring of a pathologic body image could be associated with the inability to regulate affect. As expected, ED patients scored high on the TAS-20 items. Therefore, our data agree with the literature in stating that ED patients tend to be alexithymic. ${ }^{4}$

Our study points out that affective elements of alexithymia seem to be strongly correlated with EDs; instead, the scores obtained on the cognitive factor (ie, externally oriented thinking) do not differ from those observed in the general population. This latter point confirms recent findings by other authors. ${ }^{28,29} \mathrm{We}$ add that the presence of purging behaviors does not appear to influence affect dysregulation, as no statistically significant differences were found among the three different groups (AN, BN, and EDNOS) on the TAS 20 scale and on its subscales. Our data also suggest that the ED subjects have a remarkable clinical presence of problems related to feelings of shame and troubles associated with their body image.

In fact, the average score obtained in the shame scale (mean value of ESS = 67.4) is placed over the 90th percentile compared to the Italian sample (average ESS $=45.72),{ }^{15}$ while the dissociation-related values appear to be increased (mean value DES-II $=21.6$ ) in comparison with the Italian population (mean DES-II $=12.50$ ). Besides, the average value related to the traumatic perceived conditions (weighted average TSI-A = 1.26) is higher in our sample than in the control population. ${ }^{15,27}$ These results are only marginally influenced by participant age.

Alexithymia, shame, and affect dysregulation are strictly related as demonstrated by the correlations observed in our study; our data agree with the findings of De Berardis et al. ${ }^{7}$ In their paper, the researchers noticed that dissociative experiences may be related to childhood neglect and abuse history; ${ }^{30}$ a history of abuse and neglect are observed more frequently in subjects with EDs, and in particular, among bulimic patients. ${ }^{31}$ Moreover, both childhood physical and sexual abuse appear to be associated with emotional dysregulation. ${ }^{32}$ Therefore, the authors state that alexithymia and dissociation may share common backgrounds, and that both can manifest in patients with EDs based on frequent traumatic experiences during childhood. Our study supports this hypothesis by adding the TSI-A data that show that perceived traumatic events are higher in an ED sample than in the general population, and that greater pathologic values are evident when purging behaviors are present. The role of trauma was thus deepened, and we found that subjects who score high in a trauma scale show higher shame and body dissatisfaction than those who 
score low on a trauma scale $(P<0.0001)$. We then wanted to verify how the interrelated experiences of shame and body image disturbance behave, irrespective of previous traumatic experiences. By introducing partial correlations, we found that when the impact of TSI-A is filtered, a strong correlation between shame scores and body dissatisfaction is maintained. Therefore, the link between feelings of shame and the perception of an adverse body image does not appear to be primarily determined by previous threatening events that may instead act as an aggravating factor.

Even if alexithymia seems to be unaffected by the diagnostic category, we stress that the other investigated variables (shame, dissociation, and perceived traumatic conditions) are more severe when purging behaviors are present. The same consideration can be applied when analyzing the BUT results that reflect discomfort over one's own body.

By multiple regression analysis we tried to investigate whether alexithymia could be associated with the structuring of an adverse image disorder, as the link between affect dysregulation and EDs has not been fully clarified. This hypothesis could be confirmed only partially; in fact, shame seems to hold a prevalent role in the structuring of body image disorder as it explains more than $50 \%$ of variance in the BUTGSI scores both in anorexic and in bulimic patients. The only factor of an alexithymic construct that seems to play a role in EDs is "difficulty in identifying feelings," as it explains one-third of BUT-PST in patients with AN. The inability of an individual to discriminate between emotional states may thus represent an affective vacuum that determines an exaggerated focus on the physical details of one's own body. Furthermore, when interpreting our Bonferroni test results, alexithymia could be interpreted as a function of an individual's shame-based inability to process emotions. Perceived traumatic conditions are instead strongly relevant in justifying the BUT scores when purging behaviors are present. In this view, the results noted in Mitchell and Mazzeo's ${ }^{31}$ study are supported; moreover, trauma could be somewhat causative in determining a distorted relationship with one's own body in patients who engage in purging behaviors.

By analyzing our data, we noticed that alexithymia seems partially associated with adverse image disorders. Even if the findings acquire relevance when restrictive conditions are present, it seems as though alexithymia is mostly a covariant of other psychopathologic traits or experiences, at least in bulimic patients.

Shame appears to play a prevalent role in anorexic patients, and perceived traumatic conditions appear to be influence both bulimic patients, and individuals with overlap- ping diagnoses; alexithymia may thus be a consequence of previous traumatic experiences and feelings of shame that have remained unelaborated, and this condition may be somehow conceptualized as a maladaptive-reactive construct.

Depressed mood, which is a frequent condition in ED patients, could influence shame, body dissatisfaction, and the other explored symptoms. However, despite a strong correlation between depression and alexithymia, as well as shame and adverse body image, their impact appears to be moderated when partial correlation analysis filters the effects determined by the ESS results. Regression analysis shows instead that depressed mood could be partly explained by shame and body dissatisfaction levels alone. Indeed, our tests seem to confirm that shame plays a central role in alexithymia among ED patients.

However, our study has some limitations that may have impacted the discussed considerations. In fact, the use of self-report tests, although reliable and widely used, cannot exclude the existence of patients who underreport or overreport their symptoms. Moreover, to our knowledge, regression analysis investigating the relationship between alexithymia, shame, dissociation, trauma, and body perception has never been conducted on a control population. In addition, the choice to include only women in our sample improves population homogeneity, but it prevents the authors from discussing the influence of gender in this field of ED psychopathology. Finally, it is important to keep in mind that when some variables are interrelated, it is important to explore how they are linked to each other since the presence of covariants is possible.

Therefore, more data are needed in order to confirm our study's findings. In particular, future areas of investigation could explore the role of disgust with one's own body and its relationship with feelings of shame. Recent advances in neuropsychology and functional neuroimaging techniques could add valuable information.

On the basis of our results, we want to point out that the sense of shame and previous traumatic experiences in patients with purging behaviors should be targeted during treatment.

\section{Acknowledgment}

The authors wish to thank FANEP Onlus (Famiglie di Neurologia Pediatrica) for its support and daily assistance to children and their families.

\section{Disclosure}

The authors report no conflicts of interest in this work. 


\section{References}

1. Zackheim L. Alexithymia: the expanding realm of research. J Psychosom Res. 2007;63(4):345-347.

2. Fairburn CG, Cooper Z, Shafran R, Wison GT. Eating disorders: a transdiagnostic protocol. In: Barlow DH, editor. Clinical Handbook of Psychological Disorders: A Step-by-Step Treatment Manual, 4th ed. New York: Guilford Press; 2008:578-614.

3. Striegel-Moore RH, Cachelin FM. Etiology of eating disorders in women. Couns Psychol. 2001;29:635-661.

4. Corcos M, Guilbaud O, Speranza M, et al. Alexithymia and depression in eating disorders. Psychiatry Res. 2000;93(3):263-266.

5. Karukivi M, Hautala L, Korpelainen J, et al. Alexithymia and eating disorder symptoms in adolescents. Eat Disord. 2010;18(3):226-238.

6. Speranza M, Loas G, Wallier J, Corcos M. Predictive value of alexithymia in patients with eating disorders: a 3-year prospective study. J Psychosom Res. 2007;63(4):365-371.

7. De Berardis D, Serroni N, Campanella D, et al. Alexithymia and its relationships with dissociative experiences, body dissatisfaction and eating disturbances in a non-clinical female sample. Cognit Ther Res. 2009;33(5):471-479.

8. Iancu I, Cohen E, Yehuda YB, Kotler M. Treatment of eating disorders improves eating symptoms but not alexithymia and dissociation proneness. Compr Psychiatry. 2006;47(3):189-193.

9. Taylor GJ, Parker JD, Bagby RM, Bourke MP. Relationships between alexithymia and psychological characteristics associated with eating disorders. J Psychosom Res. 1996;41(6):561-568.

10. Hund AR, Espelage DL. Childhood emotional abuse and disordered eating among undergraduate females: mediating influence of alexithymia and distress. Child Abuse Negl. 2006;30(4):393-407.

11. Speranza M, Corcos M, Loas G, et al. Depressive personality dimensions and alexithymia in eating disorders. Psychiatry Res. 2005;135(2): 153-163.

12. Everill JT, Waller G. Dissociation and bulimia: research and theory. Eur Eat Disord Rev. 1995;3(3):129-147.

13. Farrington A, Waller G, Neiderman M, Sutton V, Chopping J, Lask B. Dissociation in adolescent girls with anorexia: relationship to comorbid psychopathology. J Nerv Ment Dis. 2002;190(11):746-751.

14. Tutkun H, Savas HA, Zoroglu SS, Esgi K, Herken H, Tiryaki N. Relationship between alexithymia, dissociation and anxiety in psychiatric outpatients from Turkey. Isr J Psychiatry Relat Sci. 2004;41(2): $118-124$.

15. Caretti V, Craparo G, Schimmenti A. Fattori di rischio della dipendenza patologica in adolescenza. [Risk factors in pathological dependencies in adolescence]. Infanzia e Adolescenza. 2006;5(3):160-169. Italian.

16. Schore AN. Early shame experiences and infant brain development. In: Gilbert P, Andrews B, editors. Shame: Interpersonal Behavior, Psychopathology, and Culture. New York: Oxford University Press; 1998:57-77.

17. Bromberg PM. Treating patients with symptoms - and symptoms with patience: reflections on shame, dissociation, and eating disorders. Psychoanal Dialogues. 2001;11(6):891-912.
18. Troop NA, Redshaw C. General shame and bodily shame in eating disorders: a 2.5-year longitudinal study. Eur Eat Disord Rev. 2012; 20(5):373-378.

19. Bernstein EM, Putnam FW. Development, reliability, and validity of a dissociation scale. J Nerv Ment Dis. 1986;174(12):727-735.

20. Caretti V, Craparo G, Schimmenti A. Fattori evolutivo-relazionali dell'addiction. Uno studio sulla dipendenza da eroina [Developmental and relational factors in addiction. A study about heroin dependence]. In: Caretti V, La Barbera D, editors. Addiction. Aspetti Biologici e di Ricerca [Addiction. Biological and Research Aspects]. Milano: Raffaello Cortina Editore; 2010:99-134. Italian.

21. Bagby RM, Parker JD, Taylor GJ. The twenty-item Toronto Alexithymia Scale-I. Item selection and cross-validation of the factor structure. J Psychosom Res. 1994;38(1):23-32.

22. Haviland MG, Reise SP. Structure of the twenty-item Toronto Alexithymia Scale. J Pers Assess. 1996;66(1):116-125.

23. Briere J; PAR Staff. Trauma Symptom Inventory ${ }^{T M}$. Odessa, FL: Psychological Assessment Resources, Inc; 1995.

24. Cuzzolaro M, Vetrone G, Marano G, Garfinkel PE. The Body Uneasiness Test (BUT): development and validation of a new body image assessment scale. Eat Weight Disord. 2006;11(1):1-13.

25. Andrews B, Qian M, Valentine JD. Predicting depressive symptoms with a new measure of shame: the Experience of Shame Scale. $B r J$ Clin Psychol. 2002;41(Pt 1):29-42.

26. Caretti V, Craparo G, Schimmenti A. Il ruolo della disregolazione affettiva, della dissociazione e della vergogna nei disturbi del comportamento alimentare. [The role of affective dysregulation, dissociation and shame in eating disorders]. In: Caretti V, La Barbera D, editors. Addiction. Aspetti Biologici e di Ricerca [Addiction. Biological and Research Aspects]. Milano: Raffaello Cortina Editore; 2010:135-165. Italian.

27. Caretti V, Craparo G, Ragonese N, Schimmenti A. Disregolazione affettiva, trauma e dissociazione in un gruppo non clinico di adolescenti. Una prospettiva evolutiva. [Affective dysregulation, trauma and dissociation in a non-clinical group of adolescents. A developmental perspective]. Infanzia e Adolescenza. 2005;4(3):170-178. Italian.

28. Fenwick AS, Sullivan KA. Potential link between body dysmorphic disorder symptoms and alexithymia in an eating-disordered treatmentseeking sample. Psychiatry Res. 2011;189(2):299-304.

29. Lawson R, Emanuelli F, Sines J, Waller G. Emotional awareness and core beliefs among women with eating disorders. Eur Eat Disord Rev. 2008;16(2):155-159.

30. Kaplow JB, Saxe GN, Putnam FW, Pynoos RS, Lieberman AF. The long-term consequences of early childhood trauma: a case study and discussion. Psychiatry. 2006;69(4):362-375.

31. Mitchell KS, Mazzeo SE. Mediators of the association between abuse and disordered eating in undergraduate men. Eat Behav. 2005;6(4):318-327.

32. Paivio SC, McCulloch CR. Alexithymia as a mediator between childhood trauma and self-injurious behaviors. Child Abuse Negl. 2004;28(3):339-354.
Neuropsychiatric Disease and Treatment

\section{Publish your work in this journal}

Neuropsychiatric Disease and Treatment is an international, peerreviewed journal of clinical therapeutics and pharmacology focusing on concise rapid reporting of clinical or pre-clinical studies on a range of neuropsychiatric and neurological disorders. This journal is indexed on PubMed Central, the 'PsycINFO' database and CAS.

\section{Dovepress}

The manuscript management system is completely online and includes a very quick and fair peer-review system, which is all easy to use. Visit http://www.dovepress.com/testimonials.php to read real quotes from published authors. 